\title{
Dental Scout
}

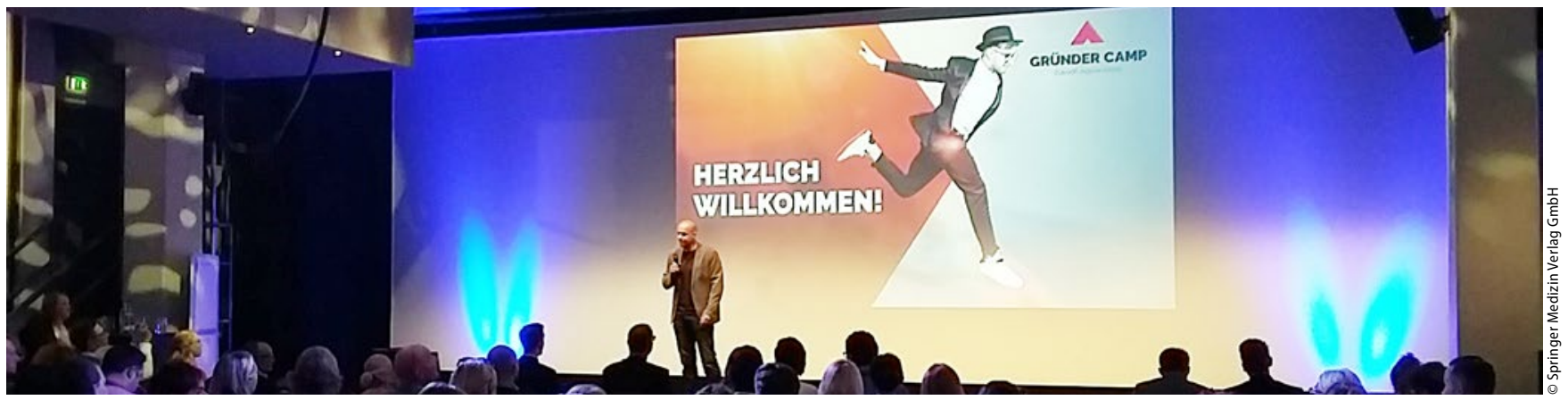

\section{Gründer Camp: Der Weg in die Selbstständigkeit}

Eine der Besonderheiten des Zahnarzt-Berufes, verglichen mit vielen anderen akademischen Berufen, ist die Möglichkeit, sich relativ einfach selbstständig zu machen. Relativ einfach deshalb, weil das Ausüben der Tätigkeiten weder große Maschinen noch viele Mitarbeiter erfordert. Doch der Schritt in die Selbstständigkeit kann durchaus herausfordernd sein. Starthilfe gab es beim dent.talents. (by Henry Schein) Gründer Camp am 29. und 30. September 2017 in Frankfurt.

Sein eigener Chef sein, nicht mehr wegen jeder Kleinigkeit, wegen jedem Tag Urlaub um Erlaubnis bitten müssen, die Arbeit selbst organisieren - das ist wohl der Antrieb vieler, sich selbstständig zu machen. Informationen und Erfahrungsaustausch bot das Gründer Camp Ende September in Frankfurt.

\section{Acht Praxisgründer in $\mathbf{8 0}$ Minuten}

Entsprechend startete das Gründer Camp am Freitagmittag mit acht Praxisgründern, die in insgesamt 80 Minuten in kurzen Vorträgen beschrieben, wie ihr individueller Weg in die Selbstständigkeit aussah, aber auch mit welchen Rückschlägen sie konfrontiert waren. Alle hatten innerhalb der letzten vier Jahre eine Praxis gegründet oder übernommen. Sie schilderten zum Beispiel die innere Blockade bei der Vorstellung, eine Praxis und die damit verbundene organisatorische, aber auch finanzielle Verantwortung zu übernehmen. Eine Lösung: Nicht immer muss direkt der "große Berg“ bestiegen werden, es kann zunächst auch ein kleiner Hügel - also die Übernahme einer relativ kleinen Praxis - sein. Ist hier erst einmal alles vorbereitet, erscheint selbst der Mount Everest nicht mehr ganz so groß. Dabei hilft es auch, sich auf seine Stärken zu besinnen und die eigene Praxis dementsprechend auszurichten und zu positionieren.

So unterschiedlich die Gründer, so unterschiedlich waren auch ihre Geschichten: Es wurde deutlich, dass es nicht nur „den einen“ Weg zur Gründung gibt. Im Anschluss an diesen Einstieg in das Gründerwochenende hatten die rund 100 Teilnehmer Gelegenheit, ihre Fragen an die Praxisgründer zu richten. Hierzu war für jeden Gründer ein Stehtisch vorbereitet, sodass Diskussionen in kleiner Runde und angenehmer Atmosphäre möglich waren.

\section{Tipps von Experten}

Am Nachmittag ging es dann ,an's Eingemachte“: Expertenvorträge zu den Themen Praxiskonzept, Businessplan, Zeitreise Existenzgründung, Marketing und Personalführung/Kommunikation standen auf dem Programm - und auch hier gab es zwi- schendurch die Möglichkeit, Fragen an die Experten zu stellen und zu netzwerken.

So erhielten Gründungsinteressierte viele Tipps, beispielsweise dazu, wie man sein Konzept der Bank verkauft. Wie hoch ist die Wahrscheinlichkeit, dass Sie den Kredit nicht zurück zahlen können? Ist Ihr Vorhaben gut geplant? Sind Sie ein Unternehmertyp, der ein Unternehmen führen kann? - all das sind Fragen einer Bank.

Für eine gut funktionierende Praxis sind gute Mitarbeiter und ein gutes Teamgefühl bedeutend. Wie schnell Teambildung gehen kann, konnten die Teilnehmer selbst erleben: Aufgeteilt in mehrere Gruppen traten sie in einem kleinen Gewinnspiel gegeneinander an. Das Fazit: Nichts verbindet Menschen so schnell zu einem Team wie ein gemeinsames Ziel. Umso wichtiger also, dass alle Mitarbeiter das Ziel der Praxis kennen.

Nach diesem umfassenden Programm konnten die Teilnehmer den Abend mit einer Party ausklingen lassen.

\section{Workshops und Breakout-Runden}

Der Samstag stand ganz im Zeichen von Workshops und Breakout-Runden. Dabei konnte jeder Teilnehmer seinen Tag durch die Wahl von zwei Workshops und drei Breakout-Runden individuell gestalten. Zur Auswahl standen bei den Workshops: CAD/ CAM, Laser, Ergonomie und Vergrößerung, Implantologie, Endodontie und Business-Start-Up: Ja oder nein. Die Breakout-Runden umfassten die Themen Hygiene, Rechtsformen und rechtliche Stolpersteine, Praxisplanung, Röntgenüberblick, Antikorruptionsgesetz, Prophylaxe, Praxisgründung und Familie sowie Schwerpunkt Implantologie.

Zum Abschluss des Gründer Camps stand dann noch eine Podiumsdiskussion auf dem Programm.

\section{Fazit}

So umfassend informiert und vorbereitet ist der Weg zur eigenen Praxis leichter zu gehen. 